\title{
Life Cycle of a Snowman Read the story The Snowman
}

Shannon Gabbard ${ }^{1}$

${ }^{1}$ Affiliation not available

March 22, 2021

\section{Hosted file}

Life Cycle of a Snowman.pdf available at https://authorea.com/users/402183/articles/514671life-cycle-of-a-snowman-read-the-story-the-snowman 